\title{
Debates en torno a la estabilidad laboral de los agentes contratados por la administración pública nacional
}

Discussions around the labor stability for the contracted workers of the National Public Administration

Debates sobre a estabilidade de agentes contratados pela administração pública nacional

Discussions sur la stabilité des agents contractuels de l'administration publique nationale

国家公共行政部门签约代理人可能的稳定

Adolfo Nicolás Balbín ${ }^{1}$ | Universidad Nacional de La Plata

Revista Derechos en Acción ISSN 2525-1678/ e-ISSN 2525-1686

Año 4/No 12 Invierno 2019 (21 junio a 20 septiembre), 105-142

DOl: https://doi.org/10.24215/25251678e301

ORCID: https://orcid.org/ 0000-0003-2927-2918

Recibido: 05/03/2019

Aprobado: 17/06/2019

Resumen: En el presente trabajo se analiza el empleo público nacional con especial referencia al caso vinculado a los agentes contratados, y el análisis de la variable estabilidad, para poder estudiar, Constitución de la Nación mediante, la posibilidad cierta de reconocerle el derecho a la propiedad en el puesto de trabajo, a aquellas personas que, vinculadas jurídicamente con el Estado, hubieran celebrado con el mismo un vínculo jurídico de prestación personal que, desde su inicio, o bien, en el desarrollo posterior, se hubiese tornado contrario a la ley. Desde este punto, la hipótesis central del artículo escrito, lejos de negar la posibilidad de que el Estado nacional contrate a personas para desarrollar tareas que

\footnotetext{
1 Abogado (UNLP). Especialista en Derecho Social (UNLP). Profesor Adjunto en Derecho Social, Facultad de Ciencias Jurídicas y Sociales, Universidad Nacional de La Plata, Argentina. Correo electrónico: nicolasbalbin@hotmail.com
} 
no respondan a una necesidad permanente, es concebir que aquellos que hubieran sido contratados en fraude al ordenamiento jurídico, y destinados, por ende, a desempeñar tareas ordinarias para el órgano o dependencia, pueden reclamar el reconocimiento de su derecho a la estabilidad, que supone, en el mejor de los casos, la solicitud tendiente a que se lo reincorpore a su lugar de trabajo. En este paper se trabaja con una mirada constitucional de las relaciones que pueden establecerse entre el derecho del trabajo y el derecho administrativo.

Palabras claves: Agente contratado-estabilidad en el empleo-fraude a la ley.

Abstract: In this paper the national public employment is analyzed with special reference to the situation of contracted agents, and the analysis of their stability, to study, with the Constitution of the Nation in sight, the certain possibility of a right to property in the job recognition, for those persons who, legally linked with the State, had celebrated with it a legal bond of personal benefit that, from its beginning, or afterwards, became contrary to the law. From this point, the central hypothesis, far from denying the State the possibility of hiring people to develop tasks that do not respond to a permanent need, is to conceive that those who had been hired in fraud to the legal system, and destined, therefore, to perform ordinary tasks for the organ or agency, can claim the recognition of their right to stability, which, in the best case, implies the request to be reinstated to their place of work. This paper works with a constitutional view of the relationships that can be established between labor law and administrative law.

Keywords: Contracted agent-employment stability-law fraud

Resumo: Neste trabalho analisa-se o emprego público nacional com especial referência ao caso vinculado aos agentes contratados, e a análise da variável estabilidade, para poder estudar, Constituição da Nação mediante, a possibilidade certa de reconhecer o direito à propriedade no posto de trabalho, para àquelas pessoas que, legalmente ligadas com o Estado, tivessem sido celebrados com ele um vínculo jurídico de benefício pessoal que, desde seu início, ou bem, no desenvolvimento subsequente, se tivesse voltado contrário à lei. A partir deste ponto, a hipótese central do artigo, longe de negar a possibilidade de que o Estado nacional contrata pessoas para desenvolver tarefas que não respondem a uma 
necessidade permanente, é conceber que aqueles que foram contratados em fraude ao sistema legal, e destinados, portanto, a realizar tarefas ordinárias para o órgão ou agência, podem reivindicar o reconhecimento de seu direito à estabilidade, 0 que significa, na melhor das hipóteses, 0 pedido tendendo a ser devolvido ao seu posto de trabalho. Neste artigo trabalha-se com uma visão constitucional das relações que podem ser estabelecidas entre o direito do trabalho e o direito administrativo.

Palavras-chave: Agente contratado- estabilidade no emprego - fraude à lei.

Résumé: dans cet article, l'emploi public national est analysé avec une référence particulière au cas de personnel recruté, et à l'analyse de la variable de la stabilité, afin d'étudier, à travers de la Constitution de la nation, la possibilité d'une reconnaissance de propriété des postes de travail aux personnes qui, légalement liées à l'État, ont célébré avec lui un lien juridique personnel qui, depuis sa création ou ultérieurement, serait devenu contraire à la loi . À partir de là, I'hypothèse centrale de l'article, loin de nier la possibilité que l'État national engage des personnes pour développer des tâches qui ne répondent pas à un besoin permanent, est de concevoir que ceux qui ont été embauchés en fraude, et destinés, par conséquent, à accomplir des tâches peuvent revendiquer la reconnaissance de leur droit à la stabilité, ce qui, dans le meilleur des cas, implique la demande de réintégration sur leur lieu de travail. Cet article présente une vision constitutionnelle des relations qui peuvent être établies entre droit du travail et droit administratif.

Mot-clés: fraude à la loi stabilité des agents, l'emploi sous contrat

关键字: 本文对国家公共就业进行了分析, 特别参考了与合同代理人 相关的案例, 并对稳定性变量进行了分析, 以便能够研究, 通过国家 宪法, 在一定程度上承认财产权。这项工作, 对于那些与国家有法律 联系的人, 与其一起庆祝的是个人利益的法律保障, 从一开始, 或在 随后的发展中, 就会违反法律。从这一点来看, 书面文章的中心假设, 不是否认民族国家雇用人们发展不能满足永久需要的任务的可能 性, 而是要设想那些被欺计的人带到法律系统, 因此, 注定要为机关 或机构执行普通任务, 他们可以要求承认他们的稳定权, 在最好的情 况下, 这意味着要求恢复到他们的工作地点。本文的作用是对劳动法 与行政法之间可以建立的关系的宪法观点。

摘要: 代理人雇佣, 工作稳定,欺计违法. 


\section{Introducción}

En este artículo trabajamos sobre la temática del empleo público, con especial referencia al caso de los agentes contratados de la Administración Pública Nacional.

Sobre esa base, defendemos y tratamos de justificar una tesis central: que aquellas personas que celebraron un negocio jurídico con el Estado a través de la figura de los contratos de empleo -por naturaleza, transitorios o limitados en el tiempo-, y que carecen por esencia del derecho a la estabilidad, pueden reclamarla sin embargo, en aquellos casos en que el Estado hubiese materializado un uso abusivo de aquel instituto.

Para ello, trabajamos permanentemente sobre el derecho administrativo, mas teniendo en cuenta también los trascendentales aportes que al mismo efectúan tanto el derecho del trabajo así como también el derecho constitucional, concatenación que pone al descubierto una vez más, la unicidad del derecho por sobre la pluralidad -valiosa por cierto- de interpretaciones que sobre el mismo se han ido trabajando a lo largo de los años.

Hemos de destacar que, por una cuestión de espacio, decidimos trabajar sobre un tejido jurídico positivo nacional, ello sin perjuicio de que la idea central aquí analizada pueda ser fácilmente trasladable a todos los casos en que se vean involucrados agentes contratados en la órbita estatal.

Refiere esta investigación a la precarización del empelado público que, como práctica extendida, actúa en contra de las personas que hubiesen celebrado algún contrato con el Estado, yendo en contramano del principio de la estabilidad con que matiza nuestra Constitución Nacional a los vínculos de empleo público (artículo 14 bis, primer párrafo).

Tal principio, de naturaleza instrumental -ello al entenderse que a través del mismo, se pueden conquistar otros derechos elementales para el conjunto de las personas que ponen su fuerza de trabajo a disposición de otro-, es unívoco y se define por el hecho de otorgar al agente la propiedad de su puesto de 
trabajo y, con ella, la de los derechos que se derivan del buen ejercicio de un puesto dentro del Estado.

Contrariamente al mismo, se ha extendido la utilización en ocasiones abusiva de la figura de los contratados de la Administración Pública, cuya naturaleza tiende -como será desarrollada in extenso en las páginas que siguen-, a satisfacer una necesidad limitada (en el tiempo y en los hechos) del Estado. Subrayamos que nuestra posición no radica en criticar todos los casos en que se hubiera hecho uso de la figura de los contratados, sino únicamente la práctica por la que se pretende utilizar de manera desproporcionada y contra legem la misma.

En pos del objetivo general antes trazado, atravesamos por diversos apartados que pretenden exponer las ideas centrales sobre las que se afinca esta investigación. Para ello, abordamos desde la noción de empleo público y la figura de los agentes contratados junto con la práctica de su precarización (con especial énfasis en la Ley Marco de Regulación del Empleo Público Nacional), hasta el trabajo sobre el principio de la estabilidad y las diversas aristas sobre las que entendemos se puede construir una tesis crítica en orden al tópico central aquí analizado.

\section{La actuación del Estado. Órgano, cargo, oficio y agente}

Podemos decir que si el Estado es una persona jurídica pública, de existencia necesaria, con una sola y única personalidad y que, como tal, solamente puede actuar por medio de las personas físicas a las que se le confiere determinado rol y atribución, resulta normal que surja la pregunta tendiente a dilucidar el motivo por el que los actos de esas personas aparecen como manifestando la voluntad del Estado y resultan imputables al mismo.

Al respecto, fueron construidas tres teorías, aunque actualmente una sola de ellas tiene prevalencia. Así, en los dos primeros niveles nos encontramos con la teoría del mandato -según la cual las personas físicas que actúan como agentes del Estado 
son simples mandatarios de la persona jurídica estatal- y la de la representación -conforme a la que las personas jurídicas (y entre ellas el Estado), al carecer de voluntad, son representadas por personas físicas a quienes se le atribuye esa función, siendo la ley la que establece el cumplimiento de tal cometido-; ambas pasibles, sin embargo, de la misma crítica, afincada ella en el hecho de que, por su conducto, no se termina de comprender cómo el Estado, careciendo de voluntad, pudo haber llegado a designar a sus primeros representantes.

En orden a ello, es que surgió una tercera tesis, en este caso la del órgano, que parte del supuesto de que la voluntad es un atributo inherente a las personas físicas, las únicas capaces de querer, razón por la que al disponerse la organización del Estado, se previó qué personas físicas tendrían el encargo de expresar una voluntad que sería imputada al ser colectivo. El órgano así entendido, no es un ente extraño a la persona jurídica, ni un sujeto diferente de ella, sino que, contrariamente, forma parte de la misma; aquel nace con la persona jurídica pero, en el caso del Estado y sus órganos, componen una sola unidad, que no puede diferenciarse ni escindirse en sí misma. La teoría del órgano es la que prevalece hoy día (Comadira, 2018:205).

En relación a la última tesis, expresa Comadira que el funcionamiento del órgano combina un conjunto de elementos estáticos con otros dinámicos; algunos institucionales jurídicos, con otros personales o físicos, aclarando que: "Son las personas físicas, más el aditamento de las atribuciones que le son conferidas y los medios que le son otorgados para su correcto ejercicio, las que dan razón, en su conjunto, a que se pueda sostener que existe, realmente, un órgano de la Administración" (2018:207).

Sayagués Laso, al exponer sobre el elemento del órgano "voluntad humana", da cuenta que las voluntades humanas que encuadrándose en las formas establecidas, ponen en movimiento los conjuntos de atribuciones individualizadas de las personas jurídicas, constituyen el elemento que da vida y acción a los órganos. El ser humano titular del órgano, cuando actúa como tal, expresa una voluntad que vale como voluntad del órgano 
y, por lo tanto, los actos que realiza, se imputan a la persona jurídica a la que pertenece aquel. Y agrega que el ser humano, aunque absorbido por el órgano cuando actúa como titular del mismo, no pierde su calidad de persona, de sujeto titular de toda clase de derechos y obligaciones; aclarando que lo que sucede es que su voluntad desempeña un doble papel: como expresión del querer de sí mismo, en cuanto ser humano y por lo tanto persona, y como expresión del querer de la persona jurídica cuyo órgano integra (1974:187).

En el tema actuación del Estado, debemos unir el concepto de órgano que antes se explicó, a otros también fundamentales, como son las nociones de cargo, oficio y agente público.

Siguiendo a Comadira, podemos decir que por "cargo" debe entenderse el lugar o la posición que un sujeto ocupa dentro de un órgano determinado, no solo estática, sino también dinámicamente, es decir, funcionalmente. Cada cargo tiene una actividad especialmente fijada, un conjunto de atribuciones y deberes, y es individualizado por una denominación que permite clasificarlos y distribuirlos en el conjunto orgánico, agregándose que si los órganos tienen formas que pueden ser variables, los cargos, en cambio se caracterizan por responder más a un patrón fijo y estable $^{2}$ (2018:208).

Asimismo, siguiendo con el autor antes citado, diremos que "oficio" puede ser entendido de dos maneras diferentes: "como la obligación de una persona determinada de realizar cierta función del Estado o como una porción funcionalmente precisada de asuntos o cuestiones estatales, es decir, como un complejo ideal de atribuciones y poderes" (Comadira, 2018:208).

Para completar este apartado, es muy importante introducir la noción de agente público. Respecto a dicho término,

2 Esto en general, sin perjuicio de lo cual nos parece importante destacar que, en la hora que corre dentro de la organización administrativa, los cargos pierden, en ocasiones, este carácter estable del que habla Comadira, concepto que nos sirve para distinguir -en un inicial aspecto-, tal componente del órgano, ello aún (se reitera), de que tengamos necesariamente que adoptar ese criterio no de manera rígida, sino más bien como lineamiento general en la definición y comparación, efectuadas. 
podríamos citar una discusión teórica que se ha dado en la doctrina administrativista, en cuanto algunos trataron de distinguir al empleado público del funcionario público, aunque sin demasiado éxito en la teoría o práctica del derecho, ello contra una tesis contraria. En dicha senda, los defensores de aquella distinción, señalaron que mientras los funcionarios eran los encargados de decidir, en calidad de representantes de la voluntad del Estado, los empleados estaban llamados a ejecutar, realizando los comportamientos materiales para llevar a la práctica las decisiones de los funcionarios.

Rafael Bielsa, alineado en esa postura, manifestó que en la actividad administrativa intervenían dos clases de órganos, lo que daba origen también (según expresó), a la distinción entre funcionarios y empleados. Los primeros deciden, y los segundos ejecutan, entendía. Amén de ello, agregó que esta distinción de carácter metódica no significaba que la separación de esos actos determinase en todos los casos la intervención de dos órganos, porque a veces podía realizarlo un solo funcionario (1955:77).

Más otro sector de la doctrina, cuyas opiniones compartimos, desmiente esa distinción basada en un aspecto meramente funcional o material, a la par que defiende la idea de que tanto los empleados como los funcionarios deciden y ejecutan en el cotidiano de su desempeño, ello aun cuando se puedan encontrar naturales diferencias en sus tareas o nivel de responsabilidad. En esa línea, señala Gordillo que aquella diferenciación fundada en el supuesto poder decisorio dista mucho de tener sustento jurídico o real, ya que no es posible hallar agente alguno de la Administración que tenga por función exclusiva la de decidir o la de ejecutar; a lo que suma dicho autor que en el derecho positivo argentino y supranacional no se hacen diferenciaciones entre funcionarios y empleados, sino que por el contrario se establece que todos los agentes de la Administración tienen la misma calificación jurídica (Gordillo, 1997:XIII-2). 


\section{El empleo público nacional. Definición general. Naturaleza. Empleo público y empleo privado. La Ley 25.164: el especial caso de los contratados}

Siguiendo la línea del apartado anterior, y complementándola, señalaremos que en cuanto a la noción del órgano (u órganos) como motor para el cumplimiento de la función estatal -subordinada, en todos los casos, al ordenamiento jurídico-, cabe mencionar que los mismos son personas de existencia ideal, que no pueden actuar y desenvolverse por sí mismos, sino que requieren de la presencia de personas físicas, por medio de las cuales poder llevar a cabo la actividad que les es atribuida.

En ese marco, aparece la figura del empleo o función pública (antes dijimos, rememorando a Gordillo -con el que coincidimos-, que no estamos de acuerdo con elaborar distinciones tajantes entre las figuras de empleado o funcionario), la que se define como la vinculación que se establece cuando una persona es investida por la Administración Pública, conforme a los procedimientos o modalidades legales que correspondan, para el desempeño de una función o empleo público, que acepta cumplir voluntariamente, con cierta permanencia, y por lo general de manera remunerada (Comadira, 2018:990).

A su respecto, según los límites de este trabajo, debemos tener en cuenta especialmente la Ley Marco de Regulación del Empleo Público Nacional nro. $25.164^{3}$, que en su artículo séptimo dice que el personal podrá revistar en el régimen de estabilidad, en el régimen de contrataciones, o como personal de gabinete de las autoridades superiores ${ }^{4}$.

De tal manera, se observa que la ley de mención ha destacado al empleo público como el género, pero exhibiendo

\footnotetext{
3 B.0 08/10/1999.

4 Como lo dice el profesor García Pullés, el artículo 7mo. recoge un avance que el Régimen Jurídico Básico de la Función Pública había marcado respecto del régimen del Decreto 6666/1957, en el que no se contemplaba claramente la situación de los contratados, del personal transitorio, de los agentes de gabinete, ni de los empleados ah honorem (Régimen de Empleo Público en la Administración Nacional, página 144).
} 
también a sus especies: personal permanente, contratado, de gabinete y ad honorem.

A su respecto, y en materia de contratados, el artículo noveno prescribe que: "El régimen de contrataciones de personal por tiempo determinado comprenderá exclusivamente la prestación de servicios de carácter transitorio o estacionales, no incluidos en las funciones propias del régimen de carrera, y que no puedan ser cubiertos por personal de planta permanente. El personal contratado en esta modalidad no podrá superar en ningún caso el porcentaje que se establezca en el convenio colectivo de trabajo, el que tendrá directa vinculación con el número de trabajadores que integren la planta permanente del organismo. Dicho personal será equiparado en los niveles y grados de la planta permanente y percibirá la remuneración de conformidad con la correspondiente al nivel y grado respectivo. La Ley de Presupuesto fijará anualmente los porcentajes de las partidas correspondientes que podrán ser afectados por cada jurisdicción u organismo descentralizado para la aplicación del referido régimen" (la cursiva no pertenece al original) ${ }^{5}$.

Sin perjuicio de lo anterior, es dable considerar que el empleo público en el orden nacional, se desmembra en dos regímenes generales: uno es el de la Ley 25.164, a que antes hicimos referencia, y que resulta propio del derecho público; y el otro es el consagrado en la Ley de Contrato de Trabajo

\footnotetext{
5 Por su parte, el Decreto Reglamentario nro. 1421 del 08/08/2002, contiene disposiciones como la que siguen (parte pertinente), artículo 90: "El régimen de contrataciones comprende la contratación por tiempo determinado y la designación en plantas transitorias, y estará sujeto a las siguientes previsiones: a) El personal será afectado exclusivamente a la realización de actividades de carácter transitorio o estacional, que resulten necesarias para complementar el ejercicio de las acciones y competencias asignadas a cada jurisdicción o entidad descentralizada (...). Las actividades de carácter transitorio estarán referidas a la prestación de servicios, asesoramiento técnico especializado, coordinación y desarrollo integral de programas de trabajo y/o proyectos especiales o para atender incrementos no permanentes de tareas. (...). d) El personal sujeto al régimen de contrataciones y el incorporado a plantas transitorias, carecen de estabilidad y su contrato puede ser rescindido o la designación en la planta transitoria cancelada en cualquier momento" (la cursiva no pertenece al original).
} 
nro. $20.744^{6}$, y sus normas complementarias, que vertebran el régimen de los contratados en el ámbito del derecho privado ${ }^{7}$. Aunque los dos sistemas difieren sustancialmente, ambos regímenes coinciden en el sentido de resultar generadores de una relación laboral entre el Estado empleador y sus dependientes contratados.

A su respecto, el artículo noveno de la Ley 25.164 -que antes transcribiéramos-, prevé un régimen de trabajo por tiempo determinado, que comprende exclusivamente la prestación de servicios de carácter transitorio o estacionales, no incluídos en las funciones propias del régimen de carrera y que no pueden ser cubiertos por personal de planta permanente.

Por otra parte, si bien cada una de las modalidades previstas en la Ley Marco merece un tratamiento diferente en cuanto a los derechos y obligaciones específicas de cada una de ellas, parece claro que el régimen de la estabilidad es el más beneficioso para el trabajador, toda vez que otorga derechos que para otras modalidades se deniegan, como son: la propiedad en el cargo, la asistencia social continuada, la igualdad de oportunidades en la carrera, compensaciones, indemnizaciones y subsidios, etc. (García Pullés, 2017:157).

\section{El derecho a la estabilidad laboral como garantía de los trabajadores. Definición general y algunos efectos}

Se puede denominar a la estabilidad como uno de los principios más destacables del derecho del trabajo (y con notoria

6 B.0. 27/09/1974.

7 De cualquier forma es valiosa la opinión que Gordillo expuso con respecto a este punto, en el sentido de que según él, la relación entre el agente y el Estado no es nunca solo de derecho privado, sino siempre, a lo sumo, mixta, agregando que la afirmación consistente en estudiar a ciertos trabajadores vinculados con el Estado como de derecho privado, refiere más que nada a la no aplicación de principios propios del derecho público, tales como las incompatibilidades, prohibiciones, etc., y a la aplicación de algunos principios del derecho privado, como ser una distinta estabilidad (dejamos a salvo una aclaración posterior con relación a lo último), reconocimiento del derecho de huelga, entre otros (1997, XIII-14). 
incidencia en el derecho administrativo), de carácter instrumental, que otorga al trabajador la potestad de conservar su puesto de trabajo y con él, los derechos que del mismo se desprenden (como así también las obligaciones), fijándose un límite infranqueable al empleador, respecto de la maleabilidad del contrato de trabajo, en base a las reglas protectorias emanados de la normativa de jerarquía fundamental.

En su relación con el empleado público, implica el derecho a no ser privado o separado del cargo, salvo por motivos o por causas legalmente previstas ${ }^{8}$. Miriam Ivanega considera que este derecho comprende la atribución del agente público de conservar su empleo, el nivel escalafonario alcanzado y avanzar en la carrera administrativa, siempre que se respeten las condiciones de ingreso y promoción establecidas en el régimen jurídico aplicable, y mientras no existan causales legítimas para extinguir la relación jurídica (2009:140).

Al respecto, la Carta Iberoamericana de la Función Pública establece como uno de sus criterios, la estabilidad del agente público y la protección frente a la destitución arbitraria, sin perjuicio de la duración indefinida o temporal que se establezca9.

En la misma senda, ahora en materia de responsabilidad laboral, el mentado instrumento internacional establece que el mero cambio de gobierno o la concurrencia de circunstancias o decisiones de exclusiva apreciación discrecional no podrán

8 Como lo señalan Marcelo Abal y Ricardo Sotura, el sistema de la estabilidad tiene su origen histórico en la experiencia de Estados Unidos, más precisamente en la necesidad de superar el spoil sistem, o sistema de despojo, por el cual cada gobierno entrante quitaba al saliente la inmensa mayoría de los cargos públicos, en consonancia con la concepción jeffersoniana de la democracia, según la cual las tareas propias del empleado público eran tan sencillas que cualquier persona normal podía realizarlas, por lo que carecía de sentido auto obligarse a gobernar con agentes puestos por otras administraciones, cuando bien podía hacérselo con una mayoría abrumadora de los propios, con mayor predisposición y compromiso para con la gestión (“Agentes contratados por la Administración Pública nacional. Derecho a la estabilidad", LL, nro. 2009 C, páginas 1134-1147).

9 Capítulo segundo, punto 7, apartado c. Instrumento disponible [on line] en el siguiente enlace: http://old.clad.org/documentos/declaraciones/cartaibero.pdf (fecha de consulta febrero de 2019). 
ser, por sí mismas, causas suficientes para justificar despidos o rescisiones de empleo, agregando que cuando se establezca la posibilidad de despido por incapacidad manifiesta o bajo rendimiento, se crearán los mecanismos necesarios para garantizar la acreditación objetiva de tales circunstancias. Menciona además que cuando exista la posibilidad de rescindir, individual o colectivamente, la relación de empleo de los empleados públicos por razones técnicas, económicas u organizativas que obliguen a la amortización de puestos de trabajo, la concurrencia de dichas causas deberá ser objetivamente acreditada mediante procedimientos dotados de las garantías necesarias ${ }^{10}$.

A su vez, en cuanto a las regulaciones específicas de la función directiva, se estableció que se debían incorporar reglas de permanencia que vinculen a la misma con los resultados de gestión, y establezcan alguna clase de protección frente a la destitución arbitraria ${ }^{11}$.

Toda la anterior discusión se dio en un terreno en donde ya había entrado en vigencia la reforma constitucional del año 1957, y su protagonista en materia de derechos sociales, el artículo 14 bis.

En él, se consagró el derecho a la estabilidad con un alcance dual, que dio paso a una larga discusión entre los especialistas de la materia y el trabajo de los magistrados que, en la mayoría de los casos, terminó con una interpretación muchas veces acotada a su respecto. Así, del texto de la norma se desprende expresamente la estabilidad para los empleados públicos y, en cuanto a la actividad privada (además de consagrarse la estabilidad para los representantes gremiales), se la intentó vincular con la protección contra el despido arbitrario.

Esta distinción surgida de la Convención Constituyente de 1957, dio paso para que en la doctrina se elaborase una muy particular clasificación de la estabilidad. Así, se dijo que

\footnotetext{
10 Artículos 45 y 46.

11 Artículo 56, punto cuarto.
} 
persistirían varios tipos de estabilidad: una de carácter absoluto -que impide la extinción del vínculo, salvo causa debidamente justificada-, y otra de carácter relativo, última ésta que a su vez fue sub clasificada como propia e impropia y que, en lo sustancial, echaría las bases de un sistema consagratorio del cuasi libre despido.

Más allá de los intentos doctrinales canalizados en los anteriores andariveles, estamos seguros de que esa creación terminológica solo sirve para aproximar la idea de estabilidad relativa al campo de la legitimidad, y que en verdad, por detrás, se está tratando de encontrar argumentos para poder maniobrar en beneficio del sujeto apropiador de la fuerza de trabajo, en base a un sistema normativo que le permite y justifica sin mayores resquicios, proceder a violentar a una persona en apariencia igual y libre (negocialmente), partiendo de la facultad que se tiene para poder despedir sin causa justificada a los trabajadores a cargo (conf. art. 245 Ley de Contrato de Trabajo nro. 20.744).

\section{Recepción legal de la estabilidad del empleado público en la Administración Pública Nacional. Algunas líneas}

Respecto a la Ley 25.164, su artículo séptimo dice que el personal podrá revistar en el régimen de estabilidad, en el régimen de contrataciones, o como personal de gabinete de las autoridades superiores, y que la situación del personal designado con carácter ad honorem será reglamentada por el Poder Ejecutivo, de conformidad con las características propias de la naturaleza de su relación. Por otra parte, se agrega en su artículo octavo que el régimen de estabilidad comprende al personal que ingrese por los mecanismos de selección que se establezcan, a cargos pertenecientes al régimen de carrera cuya financiación será prevista para cada jurisdicción u organismos descentralizados en la Ley de Presupuesto ${ }^{12}$.

12 En su parte final, el artículo octavo establece que: “La carrera administrativa básica y las específicas deberán contemplar la aplicación de criterios que incorporen los principios 
En la misma senda, el artículo 27 preceptúa que el personal vinculado por una relación de empleo público regulada por la ley de cita, y que revista en la planta permanente, no podrá ser privado de su empleo ni ser objeto de medidas disciplinarias, sino por las causas (y) en las condiciones que expresamente establece la ley.

Asimismo, el artículo 17 fija el alcance del derecho de la estabilidad, al prescribir que el personal comprendido en su régimen tendrá el derecho a conservar el empleo, y el nivel y grado de la carrera. Por su parte, el Decreto $1421 / 2002^{13}$, reglamentario de la ley marco, establece que el derecho a la estabilidad comprende la conservación del empleo, la situación escalafonaria alcanzada, en la progresión vertical y horizontal de la carrera administrativa, y la retribución asignada a la misma, mientras no se configuren las causales de cese previstas en el anexo a la ley reglamentaria.

La ley Marco del Empleo Público Nacional, norma algunos requisitos para la adquisición del derecho a la estabilidad. El primero de ellos exige que el potencial agente reúna una serie de atributos personales y profesionales considerados indispensables para el cumplimiento del cometido público al que fuera destinado.

Al respecto, y conforme surge del artículo 16 de la C.N., para ocupar cargos o empleos públicos se requiere la condición de la idoneidad. Según la opinión que en su momento expresara el profesor Miguel S. Marienhoff, la idoneidad trasunta la noción de aptitud, significando pues, la aptitud necesaria para desempeñar cargos públicos, a lo que agregó que la apreciación de la idoneidad a los efectos del nombramiento de empleados

\footnotetext{
de transparencia, publicidad y mérito en los procedimientos de selección para determinar la idoneidad de la función a cubrir, de la promoción o avance en la carrera basada en la evaluación de la eficiencia, eficacia, rendimiento laboral y de exigencias de capacitación acorde con las necesidades de las tareas o funciones a desarrollar, así como la previsión de sistemas basados en el mérito y la capacidad de los agentes, que motiven la promoción de los mismos en la carrera" (las comillas no pertenecen al original).
}

13 B.0 09/08/2002. 
o funcionarios públicos, resultaba facultad privativa del Poder Ejecutivo, sobre todo si se tenía en cuenta que la propia y más amplia función de nombrar y no solo de apreciar las condiciones personales del candidato, era por principio, facultad discrecional de la Administración Pública, ramificándose ese orden privativo en dos puntos: $1^{\circ}$ establecer objetivamente en la norma los requisitos que acreditarán la idoneidad; $2^{\circ}$ a considerar si en el caso concreto concurren o no los requisitos pertinentes (1970:116 y ss.).

En el fallo Madorrán, la CSJN dijo que la estabilidad del empleado público: "concuerda con el art. 16 de la Constitución Nacional dado que, si ha sido respetada, como es debido, la condición de idoneidad que exige esta cláusula para la admisibilidad en los empleos, es razonable pensar que el propio Estado estará interesado en continuar teniendo a su disposición un agente salvo que, si de su conducta se trata, medien razones justificadas de cese" (consid. 7mo., segundo apartado) ${ }^{14}$.

Pero coincidiendo con Miriam Ivanega, diremos que en realidad, la idoneidad es una condición para el ingreso a la Administración Pública cualquiera fuese la relación jurídica, es decir, no es exclusiva del régimen de la estabilidad, sino que los que no gozan de ella también deben ser idóneos para cumplir con la función asignada, ya sea política, administrativa, temporaria o transitoria, etc. (2009:178).

Además de la idoneidad, se deben cumplimentar según la Ley 25.164, otros requisitos a los fines de que el agente pueda gozar de la estabilidad en su empleo. A saber: a.- la existencia de una vacante incluida en la estructura del organismo como de planta permanente o estable, debidamente presupuestada, b.- el ingreso por concurso según el cargo a cubrir en el que se demuestren las condiciones de idoneidad, c.- el acto de nombramiento, y d.-el transcurso del período de prueba.

\footnotetext{
14 CSJN, "Madorrán, Marta Cristina c/ Administración Nacional de Aduanas s/ reincorporación", sent. 03/05/2007, publicada en la colección de Fallos 330:1989.
} 
En relación al primer recaudo -vacante-, es dable mencionar que según algunos autores, dicho punto está sujeto a decisiones de la Administración Pública, capaz ésta de determinar las funciones que merecen ser consideradas como de planta permanente y cuáles no, a lo que se agrega el debido respaldo presupuestario. No obstante esa explicación, que es útil, creemos que para consagrar la estabilidad del empleado público, la decisión en relación a una vacante y su respaldo presupuestario es importante, más no siempre se debe encorsetar ese derecho a tales marcos, sino que en ocasiones puede darse apertura a ciertos efectos de la estabilidad aún sin los mismos, como lo veremos posteriormente.

\section{La precarización del empleo público en el caso de los contratados}

No obstante la exposición que antes se efectuó respecto al principio de la estabilidad -con especial referencia a la Ley Marco del Empleo Público Nacional-, el caso de los agentes contratados se transforma en ocasiones en una injusta excepción a la regla estudiada.

Como ya se dijo, nuestra mirada no intenta quebrantar todas las relaciones jurídico laborales que, en la órbita del derecho administrativo, o bien en uso de normativa privada laboral, utilicen la figura de los contratos transitorios como inicio de la vinculación del agente con el Estado. Contrariamente a ello, reiteramos, nuestra crítica se dirige a los casos en que se materializa un uso abusivo de tal figura, intentando ocultar necesidades permanentes tras los mantos de negocios cualificados en esencia por su provisoriedad.

Se conduce de esa manera, a la progresiva flexibilización de las relaciones laborales (para otros, denominado fenómeno de la flexiseguridad), concepto que no solamente rige en materia del derecho del trabajo, sino que también cumple una importante función -o debiera cumplirla-, en el estudio de un derecho administrativo moderno y respetuoso de la Constitución Nacional. 
Con el concepto de flexibilización laboral se identifican diversas medidas cuyo denominador común es la desregulación de la gestión personal, ampliación de los poderes de decisión oficial, reducción de las plantas permanentes y el progreso de la negociación colectiva, no general para toda la función pública, sino fragmentada por ramas o departamentos (Ivanega, 2009:207).

Uno de los supuestos que se incluyen en esa concepción es el de la precarización laboral, que engloba todos los tipos de contratación de personal que, bajo las denominaciones de contratado transitorio o temporario, carecen para el régimen general del derecho a la estabilidad.

La figura de los empleados contratados, resulta ser un tipo de agente público previsto en todos los regímenes jurídicos, incluso en los anteriores a la década de $1990^{15}$ aunque, coincidiendo con la profesora Ivanega, de lo que se trata no es de eliminar tal forma de vinculación jurídica, sino de que la misma vuelva a su cauce natural, evitándose la generalización arbitraria de su uso en todos los estratos de la estructura administrativa.

En el terreno encargado de dilucidar la esencia de la vinculación entre el Estado y sus agentes, un sector de la doctrina entiende que la relación de empleo público tradicional es contractual, y por ende el agente sujeto a ella sería un contratado. Sin perjuicio de ello, dicha denominación se suele utilizar para identificar al personal no comprendido en los regímenes de estabilidad, que se rigen por normas que regulan un vínculo excepcional o por tiempo determinado.

El personal contratado es de antigua data en nuestra realidad nacional, habiéndose previsto tal figura hace décadas. De esa manera, la Ley $22.140^{16}$ fijaba en su artículo 13 , que el contratado debía ser afectado en forma exclusiva a la realización de 15 Como informa la Dra. Miriam Ivanega, la Ley 22.140 ya contemplaba esta categoría de
agentes.

16 B.0 25/01/1980. 
servicios que por su naturaleza y transitoriedad, no podían ser cumplidos por el personal permanente, y que no debían desempeñar funciones diferentes a las establecidas en el contrato.

Amén de lo anterior, como lo ha sostenido calificada doctrina, si bien es verdad que no resulta per se ilegítimo que el Estado contrate personal bajo una variedad de formas jurídicas, no es menos cierto que la realidad, en ocasiones, muestra un ejercicio abusivo o excesivo de la figura de los contratados a que estamos haciendo referencia. En definitiva, estos regímenes dejaron de ser excepcionales o temporarios, para convertirse en una modalidad típica habitual en el sector público (Ivanega, 2009:209-210).

La autora antes citada, entiende que dicha situación puede tener dos orígenes distintos. Por un lado la transformación de la noción de Administración Pública con la incorporación de nociones de la nueva gerencia pública y la incidencia del fenómeno de la globalización; y, por el otro, las leyes de presupuesto que derivaron en el congelamiento de las vacantes. Aunque agrega que en la práctica se verifica otro supuesto, como lo sería la supresión de cargos estables motivados en restructuraciones administrativas que originariamente responden a un nuevo diseño de organización -mayor eficacia o eficiencia-, o a razones de emergencia, todo lo cual no apareja la eliminación de funciones, sino que, por el contrario, las mismas son asignadas a personal contratado o temporario (2009:210).

Las críticas formalizadas al sistema abusivo de las contrataciones, no son solamente de actual data, sino que autores clásicos, como Miguel S. Marienhoff, proyectaron una serie de ideas a su respecto. El mismo manifestó que si bien la incorporación de personas a la Administración Pública mediante el procedimiento del contrato ad-hoc aparecía como un medio correcto y plausible, en la práctica se encontraba desprestigiado debido al abuso de que había sido objeto. Agregó, asimismo, que dicho procedimiento había sido concebido para incorporar a la Administración Pública a técnicos y especialistas cuya 
situación requería rodearlos de garantías y condiciones particulares aunque, en línea con el desprestigio señalado, detalló que la contratación se había convertido en una expresión de favoritismo hacia personas sin meritos (1970:91).

Hoy día, antes que someter a los agentes contratados a una especie de favoritismo, tal como en su época lo manifestó Marienhoff, creemos que sujeta las nuevas incorporaciones a regímenes de flexiseguridad, atentatorios de los derechos ordinarios del personal estatal, como lo es el goce de la estabilidad en el empleo.

Miriam Ivanega expresa que, amén de las características puntuales que podría tener el régimen de los contratados, dependiendo ello de la jurisdicción o provincia en que se utilice o regule, existen determinados componentes que, en general, son compartidos por dicho personal. Y entre ellos enuncia: a.- la carencia de estabilidad, de carrera administrativa, así como también el apartamiento del régimen disciplinario a que se somete el personal de planta permanente (salvo que expresamente así se establezca); b.- la duración por tiempo determinado, y que vencido el paso, no se admite la tácita reconducción; c.-ausencia de derecho de licencias, justificación o franquicias-, d.- facultad de la Administración de rescindir el contrato en cualquier momento; e.- la ausencia de derecho a indemnización cuando se decida revocar el contrato de manera anticipada (2009: 211).

\section{Defensa de la tesis favorable a la estabilidad de los agentes contratados de la Administración Pública Nacional}

En este apartado, y en el siguiente, trabajaremos sobre algunas ideas a partir de las cuales, según creemos, la tesis de la defensa de la estabilidad para los trabajadores contratados es posible. El objetivo es analizar si puede un trabajador que no ha ingresado a la planta permanente en la órbita de la Administración Pública Nacional reclamar, en determinados casos, las garantías que surgen del derecho a la propiedad del puesto de trabajo. 
Como antes se manifestó, la regla en nuestro derecho nacional es que los trabajadores de planta permanente dentro de la Administración Pública gozan de estabilidad, mientras que los agentes contratados en el mismo ámbito, no titularizan ese derecho. Amén del concierto de posibilidades con las cuales se puede limitar el derecho de la estabilidad para los agentes de planta permanente -entre las que se puede encontrar la situación de mala conducta o indebido desempeño de las actividades por parte del trabajador, o bien la supresión del empleo o cargo desempeñado, en tanto ambas no contradigan el criterio de la razonabilidad-, aquí nos limitaremos a escribir algunas líneas que apunten únicamente al caso de los agentes contratados.

Como ya se dijo, el régimen del personal contratado por tiempo determinado, tiene como finalidad cubrir necesidades especiales y temporales de la Administración, mediante la incorporación de agentes para la prestación de servicios de carácter transitorios o estacionales, no incluídos en las funciones propias del personal permanente, y que no pueden ser cubiertos por ésos últimos.

Este personal celebra con el Estado un negocio tendiente a cubrir los requerimientos especiales que se tratan de satisfacer, y cuyo fundamento puede encontrarse en el exceso de trabajo, en la necesidad de contar con técnicos o especialistas en determinadas materias, o bien en la de atender ciertas situaciones extraordinarias; destacándose en estos casos, que los agentes vinculados con el Estado carecen de estabilidad, siendo común, incluso, que en los instrumentos firmados, se consigne que a su término, los trabajadores carecen del derecho a una indemnización (Abal-Sotura, 2009:1141).

Sobre ello, destacamos que conforme nuestra convicción, la existencia en sí misma de la figura de los contratados de la Administración Pública no resulta criticable aunque, esto es importante, una idea contraria creemos que prevalece cuando media un abuso en el uso de tal figura, en tanto se recurra a la misma para que los trabajadores transitorios efectúen iguales o similares tareas a las que cumplen los empleados de planta 
permanente, exigiéndoles -no obstante-, recibir órdenes de los superiores jerárquicos, obligándolos a cumplir el mismo horario que los empleados con estabilidad, restándoles derechos de contenido asistencial, previsional o de cobertura médica, recibiendo una remuneración en concepto de honorarios, entre otras condiciones.

Es de notar que tal falseamiento de la relación contractual se agrava aún más en desmedro de los empleados contratados porque, como se dijo, éstos carecen de los derechos ordinarios que tienen sus compañeros de trabajo que cumplen, en ocasiones, idénticas labores. En esa línea, carecen (entre otros) del derecho a la estabilidad que tienen los agentes de planta permanente y de la debida protección contra el despido arbitrario, evento que se plasma cuando la Administración decide extinguir, de manera unilateral, la relación laboral (Abal-Sotura, 2009:1142).

$\mathrm{Al}$ respecto, señala Miguel Abdelnur que: "El Estado, en claro apartamiento de la legalidad, contrata a trabajadores dependientes, apelando a formas jurídicas referidas a locaciones de servicios u obras (y, como tales, independientes o autónomos), a fin de realizar tareas comunes y habituales de la Administración Pública, pero sin insertarlos en ninguna de las categorías previstas en los regímenes de aplicación, por plazos normalmente cortos, renovables o no a voluntad del funcionario de turno, y sin ningún de derecho a los beneficios que corresponden a un trabajador, especialmente en cuanto a la estabilidad -propia o impropia- en el empleo" (2014:310).

Como se advierte, tal situación resulta incompatible con el artículo 14 de la $\mathrm{CN}$-que reconoce el derecho a trabajar- y sobre todo con el 14 bis -consagratorio de la protección contra el despido arbitrario y de la estabilidad del empleado público-, lo que significa para algunos que en el empleo privado hay que proteger al trabajador frente a su despido sin justa causa, y en el público garantizarle la estabilidad laboral.

Pensamos que cuando el Estado abusa de la figura de los contratados, la solución tiene que ser otorgar al personal afectado 
la estabilidad -plena- en su puesto de trabajo, en tanto el recurso a tal forma de vinculación laboral haya resultado arbitraria, impidiendo que en los hechos pueda establecerse una tajante distinción entre el cumplimiento de tareas de un agente contratado y un compañero que pertenezca a la planta permanente. Es decir, cuando ha mediado fraude en la contratación del agente.

\section{El artículo 14 bis de la $\mathrm{CN}$ y las posibles herramientas de protección}

En orden a la defensa de la tesis que planteamos, consideramos que el artículo 14 bis de la $\mathrm{CN}$ brinda pautas claras que permiten fortalecer nuestra idea inicial. A tal fin, resulta oportuno echar uso de las diversas formas interpretativas con que se puede leer la Carta Magna, a saber: la literal, la histórica y la axiológica, conforme desarrollaremos brevemente a continuación.

En cuanto a la lectura literal, es importante remarcar que la Constitución Nacional no ha efectuado distinción alguna en relación a los diversos tipos de vinculación laboral que puedan entablarse con el Estado, y que dan origen al derecho a la estabilidad. En efecto, el artículo 14 bis primer párrafo, únicamente prescribe que los empleados públicos van a gozar de la estabilidad en su empleo. Conforme este primer criterio (que, según creemos, debe combinarse con los otros que más abajo desarrollamos), no es válido que, so pretexto de la necesidad de reglamentación de un texto estricto, se reduzcan a niveles exorbitantes los derechos laborales de quienes se relacionan con el Estado a través de un contrato de locación de servicios u obra.

A tales fines, como ha quedado plasmado en la primera parte de este trabajo, agente público -empleado o funcionario-, es toda persona física que se relaciona con el Estado para el cumplimiento de una función puntual en beneficio oficial o colectivo, ensamble en el que media una relación de jerarquía, al igual que ocurre en el contrato de derecho privado laboral, lo cual amerita que hayan surgido en nuestra escena nacional 
cláusulas como la de la estabilidad en resguardo del puesto de trabajo, directamente operativa en el caso de marras, según entendemos.

En cuanto a lo último señalado, remarcamos que si bien algunos convencionales nacionales construyeron en el año 1957 argumentos tendientes a cultivar la idea de la necesidad de leyes u otras normativas de rango inferior, posteriores a la norma cimera, encargadas de reglamentar sus cláusulas, de ello no puede colegirse que se haya conferido a la ley una autorización en blanco (en sentido metafórico) para que por su intermedio se terminaran por consagrar derechos nulos, o vacíos de contenido, para cierto grupo de agentes en caso de que se haya celebrado un contrato de locación o similar, porque una idea similar entraría en colisión no solamente con el artículo 14 bis y su visión amplia aquí defendida, sino también con la cláusula de la razonabilidad de incorporada en el art. 28 de la $\mathrm{CN}^{17}$.

Por su parte, debemos también tener en consideración en el sentido propuesto, la interpretación constitucional de tipo histórica. Al respecto, rememorando algunos conceptos e ideas trabajadas en el seno de la Convencional Nacional Constituyente de 1957, recordaremos que al discutirse la posible incorporación de la cláusula de la estabilidad, ciertos convencionales manifestaron que la intención era garantizar a los agentes vinculados con el Estado una protección contra las arbitrariedades de turno, y el mal manejo de los partidos públicos o agrupaciones similares

En dicha senda, el convencional Martella dijo que a la cláusula de la protección contra el despido arbitrario, se agregaba la estabilidad del empleado público, como una garantía de los

\footnotetext{
17 Vale recordar en esto que la CSJN ha dicho que al reglamentar un derecho constitucional, el llamado a hacerlo no puede obrar con otra finalidad que no sea la de dar a aquel toda la plenitud que le reconozca la Constitución Nacional, agregando que los derechos constitucionales son susceptibles de reglamentación, pero ésta última está destinada a no alterarlos, lo cual significa conferirles la extensión y comprensión previstas en el texto que los enunció y que manda a asegurarlos (fallo "Vizzoti c/ Amsa s/ Despido", sent. 14/09/2004, colección de Fallos 327:3677).
} 
mismos, que hasta ese momento habían tenido menor protección que los trabajadores privados, frente a la arbitrariedad de las gestiones cambiantes. A su respecto, aclaró que: "han sido la clientela fácil de los políticos, pasto de la voracidad de los comités, con gran perjuicio de los servicios generales, resentidos por los cambios frecuentes de personal y, lo que es peor, por una selección inversa de valores humanos al producirse los cambios" (Diario de Sesiones, 1958:1243).

Complementariamente a ello, el convencional Peña manifestó que el trabajador está protegido igualmente por una norma constitucional contra el despido arbitrario, afirmando que: “(...) esto es lo justo porque no se puede privar a un hombre de su medio de vida para sí y su familia por un simple capricho". Afirmando además que: "Siempre el empleado público ha estado sujeto a las cesantías en masa en ocasión de los cambios de gobierno. Ahora ya no podrá ningún partido político que conquiste el gobierno disponer de los puestos administrativos como botín de guerra. Entendemos que este principio constitucional entrará a regir simultáneamente con la vigencia de las reformas y en adelante ningún empleado público podrá ser dejado cesante sin causa justificada y sin previo sumario administrativo" (Diario de Sesiones, 1958:1254).

A su turno, el convencional Mercado afirmó, en vinculación a este ítem, que la política adquiriría sin duda una mayor jerarquía con la estabilidad del empleado público en todo el país, fundamentando esa idea al decir que el proyecto de la estabilidad tendería a asegurar económicamente a un grupo social importante, permanentemente sacrificado por los intereses excluyentes de la política demagógica, otorgándoles derechos y señalándoles obligaciones compatibles con la dignidad social humana. Con dicho pensamiento, refirió que: "Desde el punto de vista administrativo, mediante la estabilidad de los empleados y funcionarios sometidos a normas precisas, los organismos encargados de realizar la función del Estado lograrán una mayor eficacia e idoneidad, estimulando las iniciativas, la disciplina y el trabajo metódico de sus agentes. Recién entonces, podrá 
organizar científicamente el cuerpo administrativo, dotándolo de un personal de carrera, sin el peligro de las interrupciones reparadoras, que han entrañado hasta ahora, el desalojo en masa de los empleados públicos para ubicar a los correligionarios más obsecuentes y afortunados" (Diario de Sesiones, 1958:1336-1337).

Pues bien, si nos avocamos a la extensión de la protección de los agentes siempre denominados como transitorios, lejos quedaría la posibilidad de separarnos de la amplia tutela aquí propuesta, desde que con el reconocimiento de nuevos derechos para los trabajadores fraudulentamente contratados en la órbita pública, estaríamos aplicando la cláusula constitucional con los objetivos aclamados por los convencionales de antaño, socavando cualquier posibilidad de que, al margen de la ley, se agrieten derechos de contenido alimentario.

Y es que el abuso en la contratación pública, que oculta numerosas veces la intención de no gravar la responsabilidad estatal, al comisionarle a trabajadores transitorios el cumplimiento de tareas que corresponden al giro ordinario del órgano receptor, altera el contenido profundamente humano que cualifica todos los modelos de trabajo, resquebrajándose a su vez los principios de la igualdad y la no discriminación que, contrariamente a lo que suele ocurrir en las arenas descriptas, deben comúnmente dominar a todos los comportamientos públicos y privados en los que esté en juego la propia persona del trabajador ${ }^{18}$.

Asimismo, engrosando estas ideas con la normativa internacional -y nutriendo de mayor actualidad la historia de nuestro derecho supremo- podemos citar ciertos principios protectorios como los que surgen del Convenio nro. 111 de la OIT -sobre

\footnotetext{
18 A su respecto, cabe señalar que la CSJN ha expresado que garantizar la no discriminación, configura para el Estado una obligación fundamental mínima y de cumplimiento inmediato, cuya inobservancia, por acción u omisión, lo haría incurrir en un ilícito internacional (CSJN fallo "Alvarez c/ Cencosud s/ Acción de amparo", sent. 07/12/2010, colección de Fallos 333:2306).
} 
discriminación en materia de empleo y ocupación-, que actualmente tiene jerarquía supra legal. A su respecto, tal normativa obliga a los Estados parte a desarrollar una política nacional que promueva, por métodos adecuados a las condiciones y a la práctica nacional (en todo caso, a la práctica debida, y no necesariamente a la usual), la igualdad de oportunidades y de trato en materia de empleo y ocupación, con el objeto de eliminar cualquier discriminación a su respecto (art. 2).

Seguidamente, y en una línea complementaria, es dable señalar que en la Convención Constituyente de 1957 se dijo que el empleado público es una clase especial de trabajador (Diario de Sesiones, 1958:1226), pero no por ello deja de ser uno más del conjunto, sin que su engarce en el derecho administrativo pueda conducir a interpretaciones divergentes.

Axiológicamente entonces, la Constitución quiere evitar que la inconducta del Estado, o bien una conducta arbitraria de su parte, pueda alterar los derechos del grupo de agentes que se desempeñan en su ámbito, y que hacen al funcionamiento de la entidad superior.

En este sentido, es importante señalar que la ubicación metodológica de la cláusula de la estabilidad del empleado público, conllevó desde sus inicios, al inevitable ensamble entre dicho precepto y la protección contra el despido arbitrario, de ahí que no se la incorporó ni en el artículo pertinente a las facultades del Congreso, ni en el que preceptúa las atribuciones de la función ejecutiva.

Luego, encontramos presente una estrecha vinculación entre la estabilidad, y la protección frente a la arbitrariedad de quien ha requerido los servicios de un agente.

Vale rememorar que en el debate convencional, se remarcó que la garantía de la estabilidad conlleva no solamente a proteger un interés individual, sino también uno grupal, o que no excluye el contralor del Estado respecto a una buena gestión, aunque si procederes arbitrarios de su parte que pretendan corromper un derecho consolidado en cabeza de su titular. 
De manera tal que la tutela amplia esbozada, propende no solamente a proteger al agente contratado en fraude a la ley, sino también al Estado como unidad de gestión, y al resto de la ciudadanía que exige a cada momento una administración de calidad.

Todo lo dicho permite inferir que existe una íntima vinculación entre la interpretación literal, histórica y axiológica de la cláusula de la estabilidad de los agentes públicos emanada de la Constitución Nacional, que colabora para fundamentar la posición que sostenemos en esta investigación, y que da cuenta de la posibilidad de lograr una mejor protección de los intereses de los agentes contratados, reconociéndoles el derecho a la estabilidad en el empleo, en tanto la Administración Pública haya obrado en fraude a la ley laboral, pervirtiendo una autorización legal para configurar nexos transitorios, al devenir estos, en la materialidad de la función encomendada, permanentes, o simplemente al nacer como tales.

\section{Algunas líneas jurisprudenciales}

Desde una óptica general, remarcamos que nuestro Máximo Tribunal de Justicia Nacional, contrariamente a lo que postulamos en este trabajo, no participa de la opinión que pretende reconocer el derecho a la verdadera estabilidad en el empleo para los agentes contratados en fraude a la ley, o sea, cuando los mismos hubieran sido destinados a cumplir tareas permanentes del organismo estatal, sino que, en el mejor de los casos, encuentra la solución en el reconocimiento de una indemnización derivada de la extinción arbitraria del vínculo de empleo.

Con lo anterior, y superando una etapa marcadamente restrictiva en la Corte Nacional dentro de la materia estudiada -y que fuera trazada (entre otros) por los precedentes "Gil"19, 19 CSJN sent. 28/02/1988, "Gil Carlos Rafael c/ Universidad Tecnológica Nacional", colec-
ción de Fallos 312:245. 
"Leroux" ${ }^{20}$ "Stutz"21-, vale la pena señalar, aunque más no sea brevemente, algunos interesantes fallos de la CSJN dictados con posterioridad al momento antes identificado, y que sirvieron para mejorar el tratamiento de la materia, aunque en la línea antedicha.

Primero, citaremos el precedente "Ramos"22. En este caso, el actor había trabajado veintiún años para la Armada Argentina en orden a la celebración de contratos de locación de servicios, sucesivamente prorrogados, en calidad de personal transitorio. El régimen administrativo especial del organismo, permitía la contratación de personal transitorio, aunque con la particularidad de fijar un plazo máximo de cinco años, que se encontraba excedido en el caso comentado. Ramos fue cesado por razones presupuestarias, en razón de lo cual demandó al Estado Nacional a fin de obtener una indemnización por despido incausado. En las instancias de grado, la acción fue rechazada, considerando la Cámara Federal de Apelaciones de La Plata, puntualmente, que la contratación del actor se había realizado bajo un régimen que permitía pactar prestaciones de servicios personales en forma transitoria, sin que eso implicara la creación de un vínculo permanente, remarcando que el mero transcurso del tiempo no podía trastocar la situación de revista de quien había ingresado como personal no permanente, en un régimen de inestabilidad. Seguidamente, la Corte revocó el fallo, reconociendo al actor el derecho a cobrar una indemnización. Resaltan dos órdenes de cuestiones: por un lado, que del legajo del actor surgía que sus tareas carecían de la transitoriedad que suponía el mencionado régimen de excepción, que era calificado y evaluado de forma anual, que se le reconocía la antigüedad en el empleo,

20 CSJN sent. 30/04/1991, caso “Leroux de Emede, Patricia c/ Municipalidad de la Ciudad de Buenos Aires", colección de Fallos 314:376.

21 CSJN, sent. 08/05/2007, "Stutz, Oscar c/ Poder Legislativo Nacional", publicado en la colección de Fallos en 330:2206.

22 CSJN, sent. 06/04/2010, “Ramos José Luis c/ Estado Nacional (Ministerio de Defensa A.R.A) s/ indemnización por despido", Fallos 333.311. 
y que se beneficiaba con los servicios sociales del empleador; circunstancias que, unidas a la violación del impedimento a celebrar contratos por más de cinco años, permitían inferir que la demandada había utilizado figuras jurídicamente autorizadas o habilitadas para casos excepcionales, con una evidente desviación de poder, pretendiendo encubrir una designación permanente bajo la apariencia de un contrato por tiempo determinado, agregándose que el comportamiento del Estado Nacional había tenido aptitud para generar en el actor Sr. Ramos, una legítima expectativa de permanencia laboral, merecedora de la protección del artículo 14 bis; en un segundo orden, la Corte, en su considerando séptimo, trató de compatibilizar su decisión con lo resuelto en el precedente Gil (antes referenciado), afirmando que la procedencia de la demanda no se fundaba en el cuestionamiento del régimen, sino en el incumplimiento de los límites temporales en él establecidos, y la consiguiente obligación que cabía al Estado Nacional como transgresor del mismo.

En otro caso, precedente "Sanchez"23, dictado el mismo día que el anterior, la CSJN decidió rechazar la demanda -por mayoría-, mientras que la minoría integrada por los ministros Fayt, Maqueda y Zaffaroni propuso acoger el reclamo, opinión que lamentablemente no prosperó. Es de destacar que en este fallo, el actor prestó servicios ochos años en la Auditoría General de la Nación en cumplimiento de tareas propias de los empleados de planta permanente, pero por contratos sucesivamente renovados. En este caso, el régimen específico permitía esa contratación sine die de agentes y, ante su despido, el actor reclamó las indemnizaciones pertinentes, objeto que fue rechazado en primera instancia, y admitido por la Sala VII de la Cámara Nacional de Apelaciones del Trabajo. En este precedente, las opiniones que formaron la mayoría, señalaron que la específica normativa que regía a la entidad demandada, impedía considerar el tipo de tareas realizadas por los agentes

23 CSJN sent. 06/04/2010, “Sanchez Carlos Próspero c/ Auditoría General de la Nación s/ despido", publicado en Fallos 333:335. 
contratados como un indicador relevante para determinar si existía o no una relación de empleo permanente, agregándose lo que sigue: “(...) cabe considerar que el becho de que Sánchez realizara tareas típicas de la actividad de la Auditoría General de la Nación no resulta suficiente, por sí solo, para demostrar la existencia de una desviación de poder para encubrir, mediante la renovación de sucesivos contratos a término, un vínculo de empleo permanente" (consid. 5to. tercer párrafo). No obstante esta posición, la minoría destacó que la prestación laboral del actor se había desarrollado durante ocho años en tareas concernientes la actividad permanente, normal y regular de la demandada, no habiendo aportado la misma pruebas suficientes que permitiesen hacer lugar a su planteo, mediante el cual alegaba que el actor se había integrado a programas y proyectos, sin especificar en qué consistían éstos, y en qué diferían de los que regularmente aquella debía llevar a cabo.

El decisorio mayoritario en este caso resulta claramente criticable, desde que rechazaron la demanda basados solamente en la existencia de un régimen específico que permitía la celebración de sucesivos contratos con los agentes del sector, sin tomar en cuenta la materialidad de su prestación y, mucho menos, el sentido tuitivo que se desprende del artículo 14 bis de la $\mathrm{CN}$, proceder que, contrariamente a nuestro orden positivo vigente, y al prisma de los derechos constitucionales, permitiría, ilógicamente, que la excepcionalidad y la especificidad del sistema de contrataciones a plazo, pasaran a ser la regla, mientras que la permanencia constitucionalmente justificada vendría a constituirse en lo accesorio o excepcional.

Finalmente, destacamos el fallo "Cerigliano" ${ }^{24}$, caso en el cual el actor había trabajado durante siete años en tareas de operario común, suscribiendo sucesivos contratos de locación de servicios y, producido el despido, inició acciones tendientes

24 CSJN sent. 19/04/2011, “Cerigliano Carlos Fabián c/Gobierno de la Cuidad Autónoma de Buenos Aires U. Polival. De Inspecciones ex Dirección Gral. de Verif. y Control", publicado en Fallos 334:398. 
a obtener las indemnizaciones de la LCT. Contra la decisión favorable de primera instancia, la sala IV de la CNAT revocó tal sentencia, declarando inaplicable la ley laboral antedicha en razón de la inexistencia de un acto expreso conforme lo manda el artículo 2 inc. a) de la Ley 20.744, rechazando la pretensión con cita del antecedente "Leroux de Emede". En este expediente, por mayoría -la que estuvo conformada por los jueces que habían votado en minoría en la causa "Sánchez", más el Dr. Lorenzetti-, se dijo que resultaba indiscutiblemente aplicable a ese caso, el criterio expresado en "Ramos", destacando que la voluntad de la demandada de no incluir al actor en la LCT era del todo evidente y, por contraposición a la normativa específica que autorizaba a celebrar todos aquellos contratos que bajo el régimen de locación de servicios o de otra índole, se encontrasen vinculados con el objeto de la unidad ejecutora, mencionó que la misma no resultaba eficaz para enmarcar vínculos como los del actor, ajenos a la noción de transitoriedad, los que se mostraban aptos para generar razonables expectativas de permanencia. Además, la Corte señaló que la naturaleza jurídica de una institución debe ser definida, fundamentalmente, por los elementos que la constituyen, con independencia del nombre que el legislador o los contratistas le atribuyan, remarcando que resultaba evidente la desviación de poder respecto de la contratación de servicios por tiempo determinado con el objeto de encubrir vinculaciones laborales de carácter permanente (consid. quinto, último apartado). Agregó hacia el final algo importante, en cuanto habilitó para casos del estilo, la competencia contencioso administrativa, aunque, por el contenido alimentario y su mayor avance, en el caso decidió que continuara el trámite ante la justicia nacional del trabajo.

Como se advierte, si bien en los casos comentados la CSJN no reconoció el derecho a la estabilidad en el empleo, al menos sirvieron de base para la superación de la etapa restrictiva anterior, y mejoraron los derechos de los agentes contratados en fraude a la ley. 


\section{Críticas a ciertas tesis contrarias}

Como se dice en el derecho del trabajo, a necesidades permanentes corresponde la celebración de relaciones con el mismo alcance. Luego, si actuamos de manera contraria a tal regla, estaríamos discriminando a cierto grupo de agentes no alcanzados en la práctica por la estabilidad del empleado público, a pesar de los mensajes que los convencionales de 1957 pretendieron dejarnos.

Se ha dicho que no puede crearse un nuevo cargo pasando por encima de lo que corresponde al Congreso autorizar anualmente en el presupuesto general, así como tampoco generarse el mismo por vía de una sentencia de manera contraria a lo que la ley de la función pública entiende como un agente permanente. En este sentido, Pablo Gallegos Fedriani (opinión que a su vez es compartida por otros autores) ha manifestado que la procedencia de aquel argumento no es simplemente de índole económica, sino que también obedece a cuestiones de legalidad, por lo que equiparar las erogaciones no resultaría suficiente para rebatir la exigencia legal de que la partida presupuestaria y el control de la disposición legislativa que ejerce mediante ella, se vean satisfechos (2011:1283).

Amén de la respetabilidad de esa opinión, rebatimos ese argumento diciendo que la legalidad constituye en todo caso un ida y vuelta, en el sentido de que no solamente debe abarcar el proceder del agente contratado, sino también al Estado en cuanto se prohíbe al mismo destinar un empleado transitorio a cumplir prestaciones ordinarias del órgano en cuestión.

No resulta lógico, por lo demás, suspender siempre una cláusula constitucional que garantiza la estabilidad del empleado público, a partir de una ley de presupuesto o de otro carácter que, en todo caso, debe someterse a la norma cimera. La pirámide normativa de Kelsen adquiere aquí todo su sentido.

En la misma senda, como lo dice Santiago Díaz Cafferata (2009:6), citando al profesor de la Fuente, no se le puede dar prevalencia a la letra del contrato redactado, por contraposición 
a lo que surge de los hechos, es decir, al alcance de la prestación de servicios, ya que, contrariamente, sería lo mismo que decir que las partes pueden convenir válidamente apartarse de lo dispuesto por una ley imperativa, de orden público, que prohíbe expresamente que la contratación recaiga sobre tareas permanentes, admitiéndola solamente cuando tenga por objeto servicios o tareas transitorias u ocasionales ${ }^{25}$.

Es importante reiterar además, que la protección amplia emanada del artículo 14 bis de la $\mathrm{CN}$, no tiene por qué conducir, en el mejor de los supuestos, al pago de una indemnización dineraria para el agente afectado. En todo caso, la reparación debe ser, antes que en especie, in natura, traduciéndose ello en la reincorporación del agente lesionado jurídicamente, cuando el Estado hubiera procedido en fraude a la ley laboral, obstando, en consecuencia, a que pueda invocar su propia torpeza para sortear una responsabilidad mayor que le incumbe y lo alcanza.

Nos encontraríamos, pues, en el ámbito de la responsabilidad estatal por obrar ilícito, en aquellos casos en que el Estado contratare a un agente transitorio para cubrir tareas que correspondan a las normales del ámbito en cuestión. En esto vale destacar que, como lo ha dicho la Corte Suprema de Justicia (aunque no en materia administrativa, sin que tal circunstancia impida la aplicación a este caso de derecho público, de igual conclusión, sobre todo por el carácter unívoco de derecho y la ciencia jurídica) que el intercambio de violaciones de derechos humanos con dinero, entraña un conflicto con el carácter inalienable de aquellos ${ }^{26}$.

Vale recordar que el derecho al trabajo es un derecho humano y fundamental, encontrándose cualificada esa prerrogativa en el caso de los empleados públicos que desarrollen tareas permanentes, con el goce de la garantía de la estabilidad,

\footnotetext{
25 Juega aquí el denominado principio de primacía de la realidad, es decir, la prevalencia de los hechos por sobre la forma pactada o escrita.

26 CSJN fallo "Alvarez c/ Cencosud s/ Acción de amparo", sent. 07/12/2010, publicada en la colección de Fallos 333:2306.
} 
sin que la misma pueda ser objeto de retaceos indebidos, so pena de desnaturalizar la esencia protectoria emanada del artículo 14 bis de la $\mathrm{CN}$.

\section{Conclusiones}

En orden a todo lo anterior, arribamos a una serie de conclusiones que trataremos de sintetizar a continuación.

El Estado como organización social y política, actúa a través de organismos a los que se les otorga una competencia delimitada, debiendo someterse en su desenvolvimiento cotidiano -obligadamente- al ordenamiento jurídico para un correcto y legítimo funcionamiento.

En ese andar, la faceta humana del Estado (como gobierno) adquiere notoria importancia, desde que es a través de las personas que el mismo absorbe necesidades sociales, y trabaja en orden a ellas. La cara visible la constituyen, entonces, no solamente los órganos creados en orden a una política pública, sino también quienes llevan a cabo, como función propia, el cumplimiento de una porción del obrar oficial.

Son ellos los funcionarios y empleados públicos nombrados al efecto. En ese conjunto, adquiere contornos especiales la figura de los agentes contratados quienes, por ley, solamente pueden ser designados cuando media una necesidad temporalmente limitada o bien el requerimiento de un servicio que por la especialidad de su cometido, no pueda ser cumplido por el personal ordinario del ente en cuestión.

La diferencia esencial que existe entre las diversas categorías de agentes que, como base humana, prestan servicios para el Estado, radica en el goce del derecho a la estabilidad. El mismo, aun no siendo absoluto, da derechos especiales al conjunto de trabajadores alcanzados por esa garantía, en especial, la prorrogativa para conservar el puesto de trabajo, en tanto y en cuanto no medie la materialización de una falta que, por su gravedad justifique, previo sumario, la limitación de su alcance. 
Si bien los agentes contratados no gozan, como regla, del derecho a la estabilidad laboral, a una disímil conclusión podríamos arribar en aquellos casos en que el Estado, a través de la oficina o funcionario pertinente, materialice un uso desmedido de aquella figura, en tanto se exorbiten los márgenes en los que se habilita el recurso a tal forma de vinculación legal.

Tal conclusión -goce de la estabilidad para los agentes contratados-, se deriva sin deformaciones ni exageraciones del artículo 14 bis de la Constitución Nacional, en tanto otorga la estabilidad (sin distinciones) para el agente público, protegiendo además al trabajador (el agente público no deja de ser, como tal, un trabajador en relación de dependencia) al que se le hubiera extinguido su contrato de forma arbitraria.

En ese marco, invocada y probada la ilegitimidad en el obrar estatal, debe prevalecer la reparación in natura (reinstalación) antes que el resarcimiento en especie (indemnización), desde que esa es la mejor forma emanada de nuestro ordenamiento jurídico para tutelar al agente que pone su fuerza de trabajo a disposición de otro.

En esa línea, creemos que una reglamentación irrazonable del artículo 14 bis de la CN, nos distanciaría del objetivo central tenido en cuenta por los convencionales de 1957, quienes pretendieron tutelar al trabajador estatal contra los vaivenes públicos, mejorando el cometido de la función colectiva.

Como ya lo hemos puesto de manifiesto antes, el respeto a la legalidad, invocado como norte fundamental del Estado de Derecho, alcanza no solamente a las personas privadas, sino también a quienes resulten designados para cumplimentar una gestión colectiva.

Desde ese aspecto, reiteramos que es posible defender la tesis de la estabilidad de los agentes contratados por el Estado, dado cuenta de ello este trabajo que, con cita de algunos autores e ideas propias, ha tratado de justificar esa forma de pensar, punto que fuera desde el inicio el permanente incentivo para escribir estas líneas. 


\section{Bibliografía}

ABAL, M., SOTURA, R. (2009). "Agentes contratados por la Administración Pública nacional. Derecho a la estabilidad". Publicado en: Revista Jurídica Argentina La Ley, número 2009 C, páginas 1134-1147. Buenos Aires: La Ley.

ABDELNUR, Miguel Ángel (2014). "Contratados del Estado". Publicado en: Regímenes laborales especiales. Foglia, Ricardo Arturo (Director). Páginas 301 a 340. Buenos Aires: La Ley.

BIDART CAMPOS, Germán J. (1981). "Principios constitucionales de derecho del trabajo (individual y colectivo) y de la seguridad social en el art. 14 bis". Publicado en: Revista Trabajo y Seguridad Social, Año 1981, T VIII A, páginas 481 a 560.

BIELSA, Rafael (1955). Derecho Administrativo. Buenos Aires: Depalma.

CAPÓN FILAS, Enrique (2001). "Protección contra el despido arbitrario- breves apuntes para un debate. Publicado en: Revista La Causa Laboral, Asociación de Abogados Laboralistas, Año 1; $\mathrm{N}^{\mathrm{o}}$ 1, Buenos Aires, Octubre de 2001.

CARCAVALLO, Esteban (2016). "Necesidad de redimensionamiento y mejor calidad del empleo público para una eficiente gestión del Estado". Publicado en: Derecho del Trabajo, mes de octubre, pagina 2363 y ss.

CIMELLI, Darío (2010). "El fenómeno de los contratados precariamente en la Administración Pública y la voz de la corte. Nota a fallo". Publicado en: Revista Jurídica Argentina La Ley, número $2010 \mathrm{C}$, páginas 215-222. Buenos Aires: La Ley.

COMADIRA, Julio Rodolfo; ESCOLA, Héctor Jorge; COMADIRA, Julio Pablo (2018). Curso de Derecho Administrativo. Buenos Aires: Abeledo Perrot.

CORREA, José Luis (2011). "La estabilidad de los empleados contratados por el Estado". Publicado en: DJ, 12/1/2010 Buenos Aires.

DELFIN, Alejandra (2014). "Los contratados de la administración pública: cuando la sucesiva renovación de los contratos transitorios significan permanencia en el puesto". Publicado en: Revista Derecho Administrativo, número 2014 (92 Mar./Abr.), páginas 423-430. 
DIARIO DE SESIONES de la Convención Nacional Constituyente, año 1957 (1958). Buenos Aires: Imprenta del Congreso de la Nación.

DIAZ CAFFERATA, Santiago (2009). "La estabilidad del empleo público fraudulentamente contratado". Publicado en: www. eldial.com-suplemento de Derecho Administrativo.

GALLEGOS FEDRIANI, Pablo O. (2011). "Agentes contratados por la Administración”. Publicado en: Revista Jurídica Argentina La Ley, número 2011 E, páginas 1280-1285. Buenos Aires: La Ley.

GARCIA PULLES, Fernando -director- (2017). Régimen de empleo público en la Administración Nacional. Buenos Aires: Abeledo Perrot.

GOMEZ, Claudio (2011). "Los derechos del trabajador contratado por la Administración Pública desde una visión constitucional”. Publicado en: Revista La Ley, tomo C, página 322 y ss.

GORDILLO, Agustín (1997). Tratado de Derecho administrativo, Tomo 1. Buenos Aires: Fundación de Derecho Administrativo.

IVANEGA, Miriam (2009). Las relaciones de empleo público. Buenos Aires: La Ley.

JAUREGUIBERRY, Luis María (1957). El artículo nuevo. Santa Fe: Librería y Editorial Castellví S.A.

LOPEZ, Justo (1974). "El trabajador del Estado". Publicado en: Revista Derecho del Trabajo, mes de septiembre de 2012, página 2571 y ss.

MARIENHOFF, Miguel S. (1965). Tratado de Derecho Administrativo. Buenos Aires: Abeledo Perrot.

RAMELLA, Pablo A. (1986). Derecho Constitucional. Buenos Aires: Depalma.

RODRÍGUEZ MANCINI, Jorge (2010). "Los contratados en las sentencias de la Corte Suprema de Justicia de la Nación”. Publicado en: Revista Jurídica La Ley, 21/4/2010. Buenos Aires.

SAGUÉS, Néstor Pedro (1998). La interpretación judicial de la Constitución. Buenos Aires: Depalma.

SAYAGUÉS LASO, Enrique (1974). Tratado de Derecho Administrativo. Montevideo: Talleres Gráficos Barreiro y Ramos S.A. 